\title{
Rhodococcus fascians Impacts Plant Development Through the Dynamic Fas-Mediated Production of a Cytokinin Mix
}

\author{
Ine Pertry, ${ }^{1,2}$ Katerina Václavíková, ${ }^{3,4}$ Markéta Gemrotová, ${ }^{3}$ Lukáš Spíchal, ${ }^{3}$ Petr Galuszka, ${ }^{4}$ Stephen \\ Depuydt, ${ }^{1,2}$ Wim Temmerman, ${ }^{2}$ Elisabeth Stes, ${ }^{1,2}$ Annick De Keyser, ${ }^{1,2}$ Michael Riefler, ${ }^{5}$ Stefania Biondi, ${ }^{6}$ \\ Ondrej Novák, ${ }^{3}$ Thomas Schmülling, ${ }^{5}$ Miroslav Strnad, ${ }^{3}$ Petr Tarkowski, ${ }^{3,4}$ Marcelle Holsters, ${ }^{1,2}$ and \\ Danny Vereecke ${ }^{1,2,7}$
}

${ }^{1}$ Department of Plant Systems Biology, VIB, and ${ }^{2}$ Department of Plant Biotechnology and Genetics, Ghent University, Technologiepark 927, 9052 Gent, Belgium; ${ }^{3}$ Laboratory of Growth Regulators, Palacký University \& Institute of Experimental Botany, Academy of Sciences of the Czech Republic (ASCR), and ${ }^{4}$ Department of Biochemistry, Faculty of Science, Palacký University, Slechtitelů 11, 78371 Olomouc, Czech Republic; ${ }^{5}$ Institut für Biologie/Angewandte Genetik, Freie Universität Berlin, 1 Albrecht-Thaer-Weg 6, 4195 Berlin, Germany; ${ }^{6}$ Dipartimento di Biologia Evoluzionistica Sperimentale, Università di Bologna, via Irnerio 42, 40126 Bologna, Italy; ${ }^{7}$ Department of Plant Production, University College Ghent, Schoonmeersstraat 52, 9000 Gent, Belgium

Submitted 25 March 2010. Accepted 28 April 2010.

The phytopathogenic actinomycete Rhodococcus fascians D188 relies mainly on the linear plasmid-encoded fas operon for its virulence. The bacteria secrete six cytokinin bases that synergistically redirect the developmental program of the plant to stimulate proliferation of young shoot tissue, thus establishing a leafy gall as a niche. A yeast-based cytokinin bioassay combined with cytokinin profiling of bacterial mutants revealed that the fas operon is essential for the enhanced production of isopentenyladenine, trans-zeatin, cis-zeatin, and the 2-methylthio derivatives of the zeatins. Cytokinin metabolite data and the demonstration of the enzymatic activities of FasD (isopentenyltransferase), FasE (cytokinin oxidase/dehydrogenase), and FasF (phosphoribohydrolase) led us to propose a pathway for the production of the cytokinin spectrum. Further evaluation of the pathogenicity of different fas mutants and of fas gene expression and cytokinin signal transduction upon infection implied that the secretion of the cytokinin mix is a highly dynamic process, with the consecutive production of a tom initiation wave followed by a maintenance flow.

Rhodococcus fascians is a phytopathogenic actinomycete with a very broad host range that causes important commercial losses in the ornamentals industry because it triggers severe malformations of shoots, referred to as leafy galls (Depuydt et al. 2008b). In strain D188, the virulence determinants are encoded by a large conjugative linear plasmid, pFiD188 (Crespi et al. 1992), and the pathology is induced by the secretion of a mix of six synergistically acting cytokinins: isopentenyladenine

I. Pertry and K. Václavíková contributed equally to this work.

Corresponding authors: D. Vereecke; Telephone (+32) 9 2488859; Fax: (+32) 9 2424279; E-mail: danny.vereecke@ hogent.be and P. Tarkowski; Telephone (+420) 60712 6360; Fax (+420) 58563 4933: E-mail: petr.tarkowski@upol.cz

* The $\boldsymbol{e}$-Xtra logo stands for "electronic extra" and indicates that five supplementary tables and six supplementary figures are published online.
(iP), trans-zeatin (tZ), cis-zeatin (cZ), and their 2-methylthio (2MeS) derivatives (Pertry et al. 2009). In Arabidopsis thaliana, these cytokinins are perceived by the receptors AHK3 and CRE1/AHK4 (Pertry et al. 2009), activating a signaling cascade that stimulates cell proliferation and meristematic gene expression and, ultimately, results in the establishment of a specific niche (Depuydt et al. 2008a, 2009).

Comparison of the cytokinin profiles of two near-isogenic strains, D188 and its plasmid-free derivative, D188-5, has shown that a basal level of the six cytokinins is produced by a chromosomally encoded pathway. However, the much higher levels of iP, cZ, tZ, 2MeScZ, and 2MeStZ secreted by strain D188 strongly suggest an additional linear plasmid-encoded de novo biosynthetic pathway (Pertry et al. 2009). By sequence analysis of pFiD188, the fas operon was identified, consisting of six genes putatively involved in cytokinin biosynthesis and essential for virulence (Crespi et al. 1992) (Fig. 1). FasA is similar to $\mathrm{P} 450$-type cytochrome monooxygenases. The N-terminal region of FasB corresponds to 4Fe-3S-type ferredoxins of Actinomycetes, whereas its carboxy-terminus is homologous to the $\alpha$ subunit of pyruvate dehydrogenase. FasC is similar to the $\beta$ subunit of the latter enzyme. Both FasB and FasC have a binding site for the cofactor thiamine pyrophosphate (Crespi et al. 1994). FasD is an isopentenyltransferase (Ipt) protein that mediates the first dedicated step in cytokinin production (Crespi et al. 1992). FasE shows homology to plant cytokinin oxidases/dehydrogenases (CKX) (Schmülling et al. 2003), and FasF has low sequence similarity with glutathione $S$-transferases (Goethals et al. 2001). Based on these features, the following biosynthetic pathway had been postulated (Goethals et al. 2001): the P450 cytochrome monooxygenase hydroxylates the isopentenyl side chain of the cytokinin produced by FasD, while FasB and FasC deliver the required energy via the ferredoxinlike domain by using pyruvate as an electron donor; FasE does not degrade cytokinins but, instead, carries out an extra modification, possibly the addition of a glutathione or a different oligopeptide delivered by FasF.

De novo biosynthesis of $\mathrm{iP}$ and $\mathrm{tZ}$ has been well described in bacteria and plants (Sakakibara 2006). cZ, on the other hand, 
originates from tRNA degradation in Arabidopsis (Miyawaki et al. 2006) but, in other plant species, would be derived indirectly via the release from unidentified conjugates or from de novo $\mathrm{cZ}$ biosynthesis (Veach et al. 2003; Stirk et al; 2008). In bacteria, the biosynthetic pathway for $\mathrm{cZ}$ and $2 \mathrm{MeS}$ derivatives is still unclear but these cytokinins are often thought to be derived mainly or strictly from tRNA degradation (Anton et al. 2008). The tRNA of $R$. fascians has been considered to be the primary source of $\mathrm{cZ}$ and $2 \mathrm{MeScZ}$ because of the relatively constant balance between tRNA-bound and free forms in culture supernatants (Matsubara et al. 1968; Einset and Skoog 1977). R. fascians tRNA also contains iP but this cytokinin has been hypothesized to be synthesized de novo (Crespi et al. 1992).

Several approaches were taken to investigate the origin and biosynthetic pathway of the $R$. fascians cytokinins. We established the contribution of the fas operon to cytokinin biosynthesis by analyzing the cytokinin profiles of the supernatants of a fas D mutant and a fas-overexpressing strain. The enzymatic activities of FasD, FasE, and FasF were determined and the role of each of the predicted functional modules of the Fas machinery was assessed by cytokinin profiling of four fas mutants. The significance of the production of the complete cytokinin complement in virulence was addressed by infecting tobacco (Nicotiana tabacum) plants with these mutants. Finally, to get insights into the mode of cytokinin delivery into the plant tissues, we evaluated the kinetics of fas gene expression during the interaction and of cytokinin signal transduction in Arabidopsis cytokinin-receptor mutants. Based on our data, each of the Fas proteins appears to have a dedicated role in cytokinin production and virulence. To conclude, we propose an adjusted biosynthetic pathway and extend our model on the modus operandi of the $R$. fascians cytokinins.

\section{RESULTS}

The fas operon is involved in the production of cytokinins.

Previously, we have shown that $R$. fascians produces pathological levels of five of the six cytokinin bases in a linear plas-

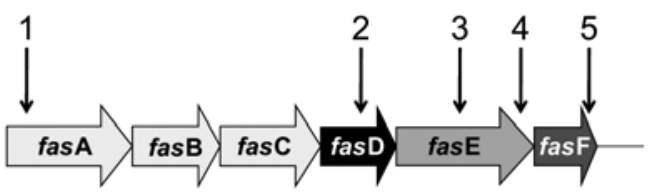
FasA
P450 monooxygenase
FasB
ferredoxin/pyruvate decarboxylase $\alpha$ subunit
FasC pyruvate decarboxylase $\beta$ subunit
FasD
FasE isopentenyltransferase cytokinin oxidase/dehydrogenase
FasF lysine decarboxylase/phosphoribohydrolase

Fig. 1. Schematic representation and (putative) enzymatic functions of the genes of the fas operon. Four functional modules of the biosynthetic machinery are shown in different gray shades. Numbered arrows mark the different fas mutants used for cytokinin and virulence profiling: 1, D188fasA; 2, D188-fasD; 3, D188-fasE; 4, D188-fas5; and 5, D188-fasF. mid-dependent manner but the direct involvement of the fas genes in this biosynthesis remained to be demonstrated (Pertry et al. 2009). Here, for the identification of fas-dependent metabolites, three strains were compared: the wild-type strain D188, the nonvirulent D188-fas 1 mutant with an insertion in the fas $\mathrm{D}$ gene (designated D188-fas D hereafter), and the D188-fas5 mutant with an insertion at the $3^{\prime}$ terminus of the fasE gene (Crespi et al. 1992) (Fig. 1) that carries a plasmid overexpressing the entire fas operon from the strong endogenous att promoter (D188-fas5OE-A/F) (discussed below). These strains were grown under fas-inducing conditions (Temmerman et al. 2000) and their supernatants were collected, extracted, and separated by high-performance liquid chromatography (HPLC), first under acidic and then under alkaline conditions. The fractions were tested in a bioassay in which conditional survival of the recombinant yeast strain $\sin 1 \Delta$ p415CYCCRE1 depends on the presence and perception of a variety of cytokinins (Inoue et al. 2001). The suitability of this assay was verified by evaluating its substrate specificity and sensitivity which showed that, whereas iP, BAP, $2 \mathrm{MeSiP}$, and $2 \mathrm{MeStZ}$ were effective already at $1 \mu \mathrm{M}, \mathrm{cZ}$ and DZ only rescued the yeast cells at very high concentrations $(100 \mu \mathrm{M})$; $\mathrm{tZ}$ and $2 \mathrm{MeScZ}$ had intermediate activities (Supplementary Fig. 1).

With this approach, two fas-dependent fractions with strong cytokinin activity were isolated. After final purification by immunoaffinity chromatography, the identity of the bioactive molecules was determined by mass spectrometry. iP, 2MeSiP, and $2 \mathrm{MeScZ}$ were detected in the active fractions of the three strains (Supplementary Table 2), confirming that $R$. fascians has a chromosomal pathway, likely tRNA turnover, that releases these cytokinins. More importantly, quantitative comparison of the biological activity of the fractions in each of the three strains revealed the fas-enhanced production of iP and $2 \mathrm{MeScZ}$ (Supplementary Fig. 2). Because the yeast bioassay was rather insensitive to $\mathrm{cZ}$ and $\mathrm{tZ}$ and $2 \mathrm{MeStZ}$ were produced in very low quantities (Pertry et al. 2009), these cytokinins could not be linked to the fas operon with this activity-based approach.

\section{The FasD Ipt produces iP and Z-type cytokinins.}

To gain more insight into the biosynthesis of the mixture of cytokinins secreted by $R$. fascians, we analyzed the enzymatic activity of the FasD, FasE, and FasF proteins. With AMP and dimethylallyl diphosphate (DMAPP) as a side-chain acceptor and donor, respectively, Ipt activity had been demonstrated in crude protein extracts of fasD-expressing Escherichia coli cells and of $R$. fascians D188 cultures grown under fas-inducing conditions but not in protein extracts of the D188-fasD mutant (Crespi et al. 1992). We reassessed the biochemical activity of FasD by heterologous expression of an N-terminal His-tagged version of the protein in E. coli (His-FasD). After purification (discussed below), the substrate specificity of His-FasD was determined by steady-state kinetic analyses. DMAPP and 4-hydroxy-3-methyl-2-(E)-but-2-enyl diphosphate (HMBPP) were tested as side-chain donors in combination with AMP, ADP, or ATP as side-chain acceptors. Similarly to other bacterial Ipt (Kakimoto 2003), His-FasD preferred DMAPP as a side-chain donor and most efficiently prenylated

Table 1. Kinetic parameters of the FasD isopentenyltransferase reaction ${ }^{\mathrm{a}}$

\begin{tabular}{lccccc}
\hline Side-chain donor & Acceptor & $\mathbf{V}_{\mathbf{m a x}}\left(\mathbf{m o l ~ s}^{\mathbf{- 1}}\right)$ & $\mathbf{K}_{\mathbf{m}}(\boldsymbol{\mu M})^{\mathbf{b}}$ & $\mathbf{k}_{\text {cat }}\left(\mathbf{s}^{-\mathbf{1}}\right)$ & $\mathbf{k}_{\text {cat }} / \mathbf{K}_{\mathbf{m}}\left(\mathbf{s}^{\mathbf{- 1}} \mathbf{M}^{-\mathbf{1}}\right)$ \\
\hline Dimethylallyl diphosphate & AMP & $8.39 \mathrm{E}-09$ & $0.030 \pm 0.016$ & $7.93 \mathrm{E}-03$ & 264,376 \\
4-Hydroxy-3-methyl-2-(E)-but-2-enyl diphosphate & AMP & $7.17 \mathrm{E}-10$ & $0.026 \pm 0.003$ & $6.77 \mathrm{E}-04$ & 26,454 \\
& ADP & $9.96 \mathrm{E}-10$ & $0.550 \pm 0.020$ & $9.42 \mathrm{E}-04$ & 1,744 \\
\hline
\end{tabular}

\footnotetext{
${ }^{a}$ Measurements were done at $25^{\circ} \mathrm{C}, \mathrm{pH} 8.0$, and the reactions were stopped at defined time points. Parameters were derived from data obtained from
} Michaelis-Menten plottings with Hyper32 software.

${ }^{\mathrm{b}}$ Mean of three measurements \pm standard deviation. 
AMP to form iP-type cytokinins (Supplementary Table 3). Nevertheless, His-FasD also utilized HMBPP as side-chain donor and hydroxyprenylated AMP and ADP, thus producing Z-type cytokinins in vitro. Consequently, although the $\mathrm{k}_{\mathrm{cat}} / \mathrm{K}_{\mathrm{m}}$ value for DMAPP was 10-fold higher than that for HMBPP (Table 1) and very little $\mathrm{tZ}$ could be detected in the supernatants of induced D188 cultures (Pertry et al. 2009), the activity of the FasD protein potentially accounts for the production of both the iP and Z-type cytokinins in the bacterial mix.

\section{FasE is a cytokinin oxidase/dehydrogenase} with a strong affinity for iP-type cytokinins.

The FasE protein is homologous to CKX of plants $( \pm 30 \%$ identity, $\pm 50 \%$ similarity) and contains the conserved N-terminal GHS motif that is involved in binding of the FAD cofactor (Supplementary Fig. 3). Although the FasE protein is also similar to hypothetical proteins from other bacteria (Supplementary Fig. 4), no functional data on these bacterial enzymes have been reported to date.

Radioactive feeding experiments provided a first glimpse of the enzymatic activity of FasE. Supernatants of D188, D188fas D, D188-fasDOE-A/F (overexpressing the complete fas operon), and D188-fasDOE-A/D (overexpressing only the first four genes of the fas operon) grown under fas-inducing conditions in the presence of $\mathrm{U}_{-}{ }^{14} \mathrm{C}$ adenine were subjected to thinlayer chromatography (TLC) analysis. A fas-dependent spot was detected that was most intense for strain D188-fasDOE$\mathrm{A} / \mathrm{D}$ in which fas $\mathrm{E}$ (and fas $\mathrm{F}$ ) was not overexpressed, suggesting that the FasE protein degrades fas-derived products. This

Table 2. Cytokinin oxidase/dehydrogenase activity of FasE ${ }^{\mathrm{a}}$

\begin{tabular}{lccccc}
\hline & \multicolumn{2}{c}{ Ferricyanide } & & \multicolumn{2}{c}{$\mathbf{O}_{\mathbf{2}}$} \\
\cline { 2 - 3 } \cline { 5 - 6 } Substrate $^{\mathbf{b}}$ & pkat/mg & $\boldsymbol{\%}$ & & pkat/mg & \% \\
\hline iP & 183.1 & 100 & & 34.8 & 100 \\
iPR & 162.9 & 89 & & 36.5 & 105 \\
iPRMP & 246.8 & 135 & & 54.2 & 156 \\
iP9G & 5.1 & 3 & & 8.1 & 23 \\
2MeSiP & 299.9 & 164 & & 37.2 & 107 \\
cZ & 45.2 & 25 & & n.d. & n.d. \\
$2 M e S c Z$ & 30.4 & 17 & & n.d. & n.d. \\
tZ & 18.9 & 10 & & 3.4 & 10 \\
$2 \mathrm{MeStZ}$ & 14.3 & 8 & & 5.1 & 15
\end{tabular}

${ }^{a}$ Substrate specificity of FasE in dehydrogenase $(500 \mu \mathrm{M}$ ferricyanide $)$ and oxidase $\left(\mathrm{O}_{2}\right)$ mode at $\mathrm{pH} 6.0$ given as absolute (pkat $\left./ \mathrm{mg}\right)$ and relative activities compared with its ability to degrade isopentenyladenine (iP) (set at $100 \%$ ). All data are mean values of four biological replicates. Deviations between replicates did not exceed $15 \%$; n.d. = oxidative degradation of cis-derivatives could not be determined due to cyclization of the degradation product (Galuszka et al. 2007).

b $2 \mathrm{MeS}=2$-methylthio-derivatives, $\mathrm{cZ}=$ cis-zeatin, and $\mathrm{tZ}=$ trans-zeatin. conclusion was supported by the gradually intensifying fasdependent spot, with increasing amounts of thidiazuron (Supplementary Fig. 5), known to inhibit CKX activity (Chatfield and Armstrong 1986).

To obtain direct evidence for the cytokinin-degrading activity of FasE, a FasE-maltose-binding protein (MBP) fusion protein was produced in E. coli. After release of FasE from the fusion protein upon factor $\mathrm{Xa}$ treatment (discussed below), the enzyme activity was tested in oxidase and dehydrogenase mode with oxygen and ferricyanide (FC) as electron acceptors, respectively. FasE preferentially acted as a dehydrogenase and efficiently degraded iP, iPR, iPRMP, and $2 \mathrm{MeSiP}$ but not iP-9glucoside (iP9G), tZ, 2MeStZ, cZ, or $2 \mathrm{MeScZ}$ (Table 2). In addition to FC, 2,3-dimethoxy-5-methyl-1,4-benzoquinone and, to a lesser extent, 2,6-dichlorophenolindophenol were suitable electron acceptors (Supplementary Table 4), indicating that the endogenous electron acceptor of FasE most probably will be a quinone.

By incubating recombinant FasE with a mixture of all six cytokinins produced by $R$. fascians and following the concentration of each individual cytokinin over a period of $2 \mathrm{~h}$, its affinity toward and the conversion rates of the different cytokinins in the mixture were assessed. Whereas iP and $2 \mathrm{MeSiP}$ were depleted from the reaction mixture within a few minutes, the Z-type cytokinins, especially the trans-isoforms, were highly resistant (Supplementary Table 5). These data confirm the strong preference of FasE for iP-type cytokinins even when present in a complex mixture.

\section{The phosphoribohydrolase activity of FasF releases cytokinin bases from their nucleotides.}

Although FasF purportedly resembled glutathione $S$-transferases (Goethals et al. 2001), new homology searches revealed that it is much more similar to lysine decarboxylases (LDC) from different organisms (Supplementary Fig. 6). Because LDC are involved in the production of the diamine cadaverine and di- and polyamines are known to influence plant morphogenesis (Baron and Stasolla 2008), the presence of cadaverine was investigated in the supernatants of D188 cultures grown under fas-inducing conditions, as well as in tissues from infected tobacco plants. Cadaverine could not be detected in any of the samples (data not shown), arguing against an LDC activity of FasF.

Interestingly, the LONELY GUY (LOG) protein of rice (Oryza sativa) that exhibits phosphoribohydrolase activity toward cytokinin nucleotides and directly releases the free bases from these precursors has been reported to be similar to FasF (Kurakawa et al. 2007). The LOG homologs of Arabidopsis are cytokinin-activating enzymes as well (Kuroha et al. 2009). Consequently, we generated a FasF-MBP fusion and tested the

Table 3. Release of individual cytokinin bases from a mixture of their nucleoside $5^{\prime}$-monophosphate precursors by the phosphoribohydrolase activity of FasF-maltose-binding protein ${ }^{\mathrm{a}}$

\begin{tabular}{|c|c|c|c|c|c|c|}
\hline Cytokinin ${ }^{b}$ & $0 \mathrm{~min}$ & $5 \mathrm{~min}$ & $10 \mathrm{~min}$ & $20 \mathrm{~min}$ & $60 \mathrm{~min}$ & $120 \mathrm{~min}$ \\
\hline tZRMP & 100 & $92.7 \pm 2.6$ & $92.7 \pm 3.3$ & $88.9 \pm 4.4$ & $79.9 \pm 12.0$ & $62.4 \pm 14.1$ \\
\hline cZRMP & 100 & $93.1 \pm 5.6$ & $95.3 \pm 5.9$ & $91.5 \pm 4.7$ & $83.5 \pm 15.6$ & $60.9 \pm 18.7$ \\
\hline iPRMP & 100 & $92.0 \pm 5.8$ & $90.0 \pm 0.7$ & $65.5 \pm 31.7$ & $55.4 \pm 23.5$ & $44.1 \pm 22.6$ \\
\hline $\mathrm{tZ}$ & 0 & $1.1 \pm 0.2$ & $3.5 \pm 0.8$ & $10.0 \pm 3.2$ & $28.5 \pm 8.9$ & $49.8 \pm 15.1$ \\
\hline $\mathrm{cZ}$ & 0 & $0.5 \pm 0.1$ & $2.5 \pm 0.8$ & $6.4 \pm 2.4$ & $17.9 \pm 6.7$ & $29.4 \pm 9.6$ \\
\hline iP & 0 & $2.4 \pm 0.4$ & $8.3 \pm 2.1$ & $21.4 \pm 6.1$ & $53.6 \pm 14.7$ & $84.9 \pm 21.1$ \\
\hline $\mathrm{tZR}$ & 0 & n.d. & n.d. & n.d. & n.d. & n.d. \\
\hline $\mathrm{cZR}$ & 0 & n.d. & n.d. & n.d. & n.d. & n.d. \\
\hline iPR & 0 & n.d. & n.d. & n.d. & n.d. & $0.2 \pm 0.1$ \\
\hline
\end{tabular}

${ }^{a}$ Initial concentration of each nucleotide was $1 \mu \mathrm{M}$ and the decrease in nucleotides and increase in free bases was followed over a period of 120 min by liquid-chromatography-mass spectrometry. The proportional increase of each free base in the reaction was related to the signal given by $1 \mu \mathrm{M}$ of the free bases. All data represent mean values of four independent experiments; $n . d .=$ not detectable.

${ }^{\mathrm{b}} \mathrm{tZ}=$ trans-zeatin, $\mathrm{cZ}=$ cis-zeatin, and $\mathrm{i} \mathrm{P}=$ isopentenyladenine. 
phosphoribohydrolase activity of FasF on a mixture of $5^{\prime}$ monophosphate (5'-MP) nucleosides of iP, tZ, and $\mathrm{cZ}$ (discussed below). The activity of FasF and FasF-MBP was comparable, indicating that the MBP tag had no effect, although it improved the stability of the protein (data not shown). The three substrates were converted into their respective free bases under the conditions tested but FasF-MBP hydrolyzed most efficiently iPR-5'-MP and least efficiently cZR-5'-MP (Table 3). These results imply that FasF potentially contributes to the level of bioactive cytokinin bases produced by $R$. fascians during its interaction with the host.

\section{The cytokinin mixtures produced}

\section{by different fas mutants are quantitatively different.}

To address the contribution of each of the functional modules encoded by the fas operon (Fig. 1) to the composition of the cytokinin spectrum, insertion mutants in fas $\mathrm{E}$ and $f a s \mathrm{~F}$ were generated via disruptive single homologous recombinations (discussed below); fasA (D188-fas6, designated D188-fasA hereafter) and fas D (D188-fasD) mutants were already available (Crespi et al. 1992, 1994). The four mutants and strains D188 and D188-5 were grown under fas-inducing conditions, and the levels of the six cytokinin bases in their supernatants were profiled by liquid chromatography-mass spectrometry. Whereas $2 \mathrm{MeStZ}$ had been detected in the supernatant of D188 (Pertry et al. 2009), its level dropped below the detection limit in all mutants tested, suggesting that the entire fas operon is implicated in $2 \mathrm{MeStZ}$ production (data not shown). The levels of the other five cytokinins were significantly altered in the different mutants, albeit to a different extent (Fig. 2A), indicating that each functional module is involved in a different step of the biosynthetic pathway.

The central position of FasD in the biosynthetic machinery was emphasized by the reduction to D188-5 levels of iP, cZ, $2 \mathrm{MeScZ}$, and $\mathrm{tZ}$ in D188-fasD (Fig. 2A). This result demonstrated that the delivery of iP through the Ipt activity of FasD represents the first and determinant step in the production of the pathological cytokinin levels.

Based on the cytokinin profiles, the putative FasA-FasBFasC-hydroxylating system seemed to be as important as the FasD function. Indeed, in the D188-fas A mutant, $\mathrm{tZ}, \mathrm{cZ}$, and $2 \mathrm{MeScZ}$ levels were similar to those measured in D188-fas D and D188-5 (Fig. 2A). In contrast, the level of iP was more than $50 \%$ higher than that of D188-fas D, confirming that the fas $\mathrm{A}$ mutation has no polar effect on fas $\mathrm{D}$ expression (Crespi et al. 1994) and indicating that iP is a substrate for FasA-mediated hydroxylation to Z-type cytokinins.

The specific in vitro activity of FasE against iP-type cytokinins was supported by the doubled iP and $2 \mathrm{MeSiP}$ levels in D188-fasE. Surprisingly, in this mutant, the levels of $\mathrm{cZ}$ and tZ, poor FasE substrates (Table 2), were similar to those detected in D188-5 but also to those of the D188-fasF mutant.

A
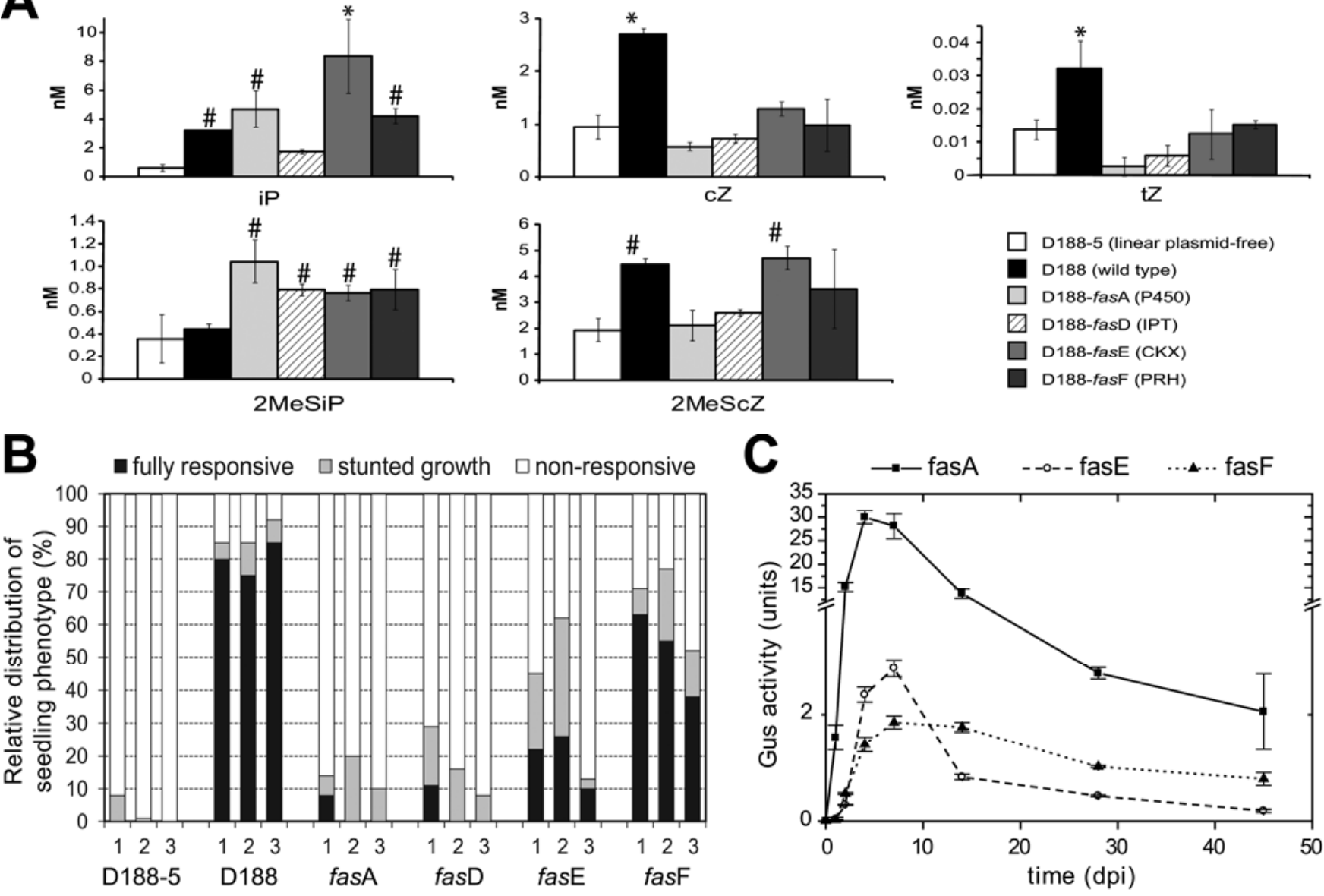

Fig. 2. Cytokinin profiles and virulence of the different fas mutants and fas gene expression during the plant interaction. A, Cytokinin production upon growth under fas-inducing conditions. Statistical differences were evaluated with the Tukey range test in conjunction with an analysis of variance; *, statistically different from all the rest; \#, statistically different from D188-5 but not from each other; no symbol, not statistically different from D188-5. Error bars represent standard deviations $(n=3)$. B, Quantification of the phenotypes of tobacco seedlings inoculated with different Rhodococcus fascians strains. At least 50 plants were scored per treatment at each time point. 1, 14 days postinfection (dpi); 2, 28 dpi; 3, 45 dpi. C, Kinetics of fas gene expression during symptom development on tobacco. 
Most likely, the fas $\mathrm{E}$ mutation has a polar effect on fas $\mathrm{F}$ expression. The strongly reduced levels of the Z-type cytokinins in D188-fasF might imply that the phosphoribohydrolase activity of FasF during the interaction with the plant is mainly involved in the release of $\mathrm{cZ}$ and $\mathrm{tZ}$ from their respective nucleotides (Fig. 2A).

$2 \mathrm{MeSiP}$ was the only cytokinin whose levels exceeded those of D188 and D188-5 in all fas mutant backgrounds (Fig. 2A), confirming the chromosome-dependent 2MeSiP biosynthesis (Pertry et al. 2009). The higher levels of this cytokinin in a $\mathrm{fas}^{-}$pFiD $188^{+}$background suggests that, in the wild type, chromosomally produced $2 \mathrm{MeSiP}$ can be used as a precursor by the Fas machinery to make other cytokinins. This hypothesis is supported by the strong increase in $2 \mathrm{MeSiP}$ in D188fas $\mathrm{A}$ which could indicate that chromosomal $2 \mathrm{MeSiP}$ is hy- droxylated by FasA to form $2 \mathrm{MeSZ}$. It is currently unclear why $2 \mathrm{MeSiP}$ accumulates in D188-fasD and D188-fasF.

The fas genes are differentially involved in virulence and are differentially expressed during the interaction.

We analyzed the correlation between the different cytokinin profiles of the insertion mutants and their capacity to inhibit tobacco seedling growth. Typically, symptoms induced in this assay can be divided into three categories: no growth inhibition (nonresponsive); intermediate growth inhibition, with malformations of developing leaves (stunted growth); and complete growth inhibition, with arrest at the cotyledonary stage (fully responsive). Infection with D188 resulted in an almost complete growth inhibition, inoculation with D188-5 did not affect seedling growth, while strains D188-fasA and D188-fasD were
A

ColO

ColO

+ D188

ahk2ahk3 control

ahk2ahk3

+ D188

ahk2ahk4
control

ahk2ahk4

+ D188

ahk3ahk4 control

ahk3ahk4

+ D188

B

\section{Col0 \\ ahk2ahk3 \\ ahk2ahk4 \\ ahk3ahk4}
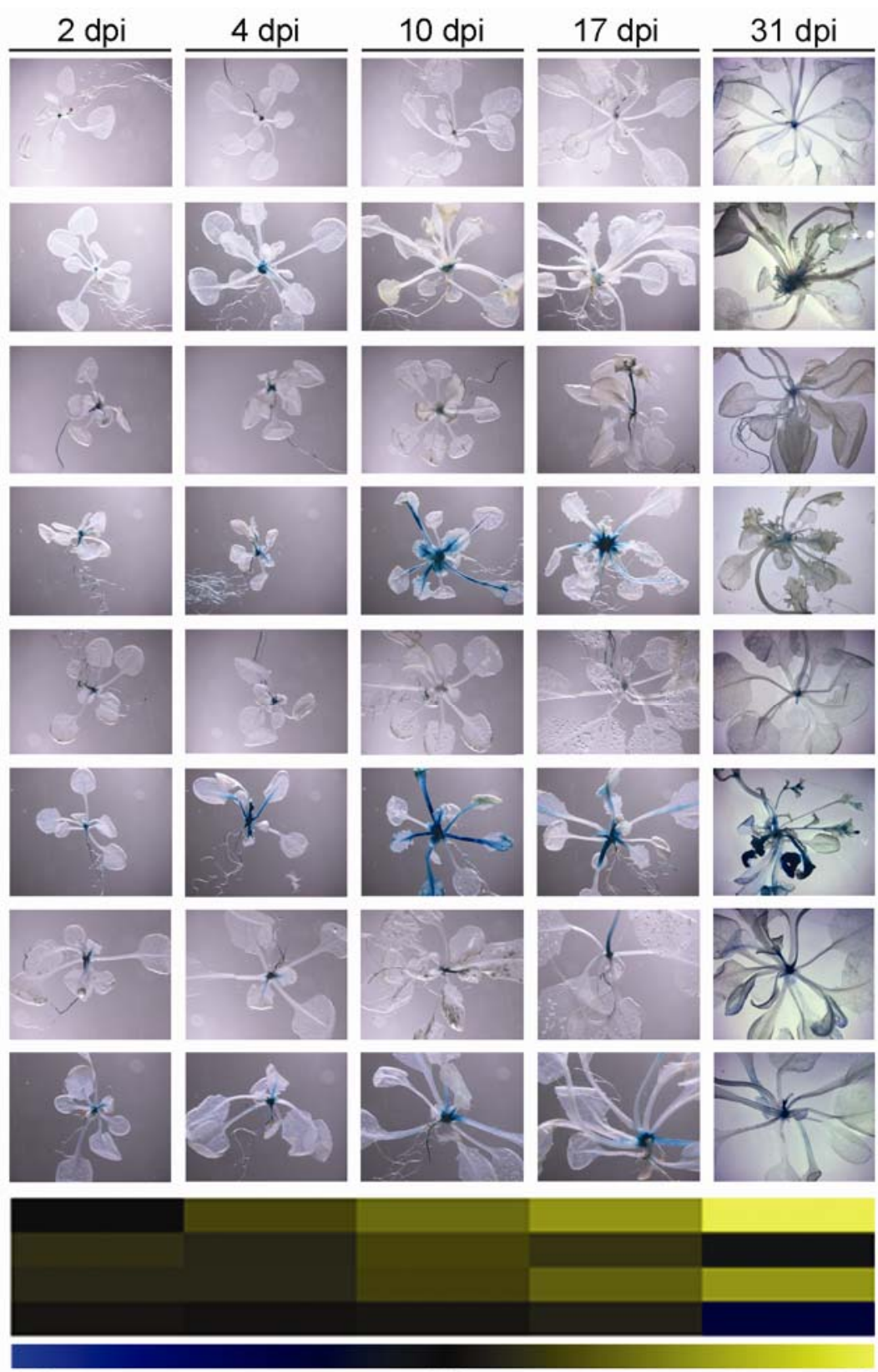

0.0

1.0

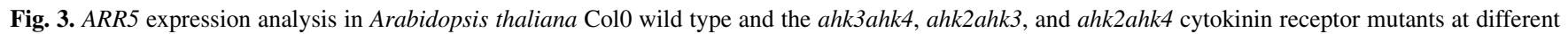
time points during interaction with Rhodococcus fascians; dpi = days postinfection. A, Histochemical visualization after mock inoculation with water (control) or infection with strain D188. B, Relative ARR5 expression measured by quantitative reverse-transcription polymerase chain reaction (log 2 transformation of fold induction of infected versus control values). 
nonvirulent (Fig. 2B). These results confirmed previous observations and illustrate the absolute requirement of FasA and FasD for virulence (Crespi et al. 1992, 1994).

The mutation in fasE generated a strongly attenuated phenotype, with most of the seedlings unaffected by the infection (Fig. 2B), implying that bacterial CKX activity is needed for establishing the symptoms. Strain D188-fasF appeared to be virulent at first, with over $60 \%$ fully responsive seedlings 14 days postinfection (dpi). However, as the interaction proceeded, symptoms disappeared (Fig. 2B): growth inhibition was relieved and $20 \%$ of the stunted seedlings resumed growth at 45 dpi. These observations indicate that the FasF-produced level of zeatin is not required for symptom initiation but is essential for symptom maintenance. The loss of symptoms between 14 and 45 dpi that was also observed for the seedlings that did exhibit growth inhibition upon D188-fasE infection most probably resulted from the polarity of the fas $\mathrm{E}$ mutation on the fas $\mathrm{F}$ expression (Fig. 2B).

To get more insight into how the fas functional modules are differentially relevant in the onset and stable establishment of the symptoms, we evaluated the kinetics of the expression of fas $\mathrm{A}, \operatorname{fas} \mathrm{E}$, and $\operatorname{fas} \mathrm{F}$ at different time points during the interaction with tobacco. The reporter strains generated for this analysis resulted from homologous integration events that disturb fas gene functioning and, hence, symptom development. Because it is plausible that the physiology of the developing symptomatic tissues is important for correct virulence gene expression (Cornelis et al. 2002), we co-infected the tobacco seedlings with D188 and the individual fas reporters. Expression of fas A was detectable already at $1 \mathrm{dpi}$, steeply increased to peak at $4 \mathrm{dpi}$, and then dropped to maintain a steady-state level from 28 dpi onward (Fig. 2C). The fasE expression profile was similar to that of fasA, although the peak occurred at 7 dpi and the level was 10-fold lower (Fig. 2C). This co-regulation might suggest that the CKX activity of FasE is required when FasA-FasD activities are high. The expression of fas $\mathrm{F}$ peaked between 7 and $14 \mathrm{dpi}$ and then gradually decreased to a steady-state level that was in the range of that of fas A (Fig. 2C).

These data show that a high fas gene expression is required at the start of the interaction to trigger symptom development and that a much lower activity mediated by both the FasA-FasD and FasF pathways is sufficient to maintain the hyperplasia.

\section{Upon perception of the $R$. fascians cytokinins, there is a differential signal transduction occurs through the individual cytokinin receptors.}

The virulence assays, the cytokinin profiles, and the fas gene expression profiles implied that each of the Fas proteins contributed to the dynamic production of cytokinins determining symptom development. Arabidopsis perceived the bacterial cytokinins via the receptors AHK3 and CRE1/AHK4 but seemingly not via AHK2 (Pertry et al. 2009). The subsequently triggered cytokinin response in wild-type plants was evidenced by an increased expression of the A-type response regulator gene ARR5 (Depuydt et al. 2008b, 2009). Although ARR5 expression also seems responsive to various abiotic stresses (Heyl et al. 2006), monitoring of this gene has been described as a rapid cytokinin-response assay in Arabidopsis (Romanov et al. 2002). Therefore, to determine whether the receptors are differentially involved in the perception of the cytokinins produced by $R$. fascians, we studied the ARR5: $\beta$-glucuronidase (GUS) expression in wild-type plants and compared it with that in the ahk3ahk4, ahk2ahk4, and ahk2ahk3 double mutants in which, in each case, only one cytokinin receptor is active (Riefler et al. 2006; Spíchal et al. 2009). Plants were infected and sampled for quantitative reverse-transcription polymerase chain reaction
(qRT-PCR) and histochemical analyses at different time points after infection.

In the wild type, an increase in $A R R 5$ expression was apparent from 4 dpi onward (Fig. 3A and B), confirming previous data (Depuydt et al. 2008b, 2009). For those lines that retained a functional AHK3 or CRE1/AHK4, the receptors implicated in bacterial cytokinin perception, ARR5 expression was still induced but the maximum induction levels were much lower than that observed in wild-type plants (Fig. 3A and B). Moreover, whereas ARR5 expression continued to increase throughout the experiment when AHK3 was the only functional cytokinin receptor, ARR5 induction was transient and completely faded between 17 and 31 dpi when only CRE1/AHK 4 was active (Fig. 3A and B). When AHK2 was the only functional receptor, hardly any differential ARR5 expression was detected upon infection (Fig. 3A and B).

\section{DISCUSSION}

The importance of the fas operon in leafy gall induction was established many years ago (Crespi et al. 1992) and the role of cytokinins in the symptomatology had long been anticipated (Thimann and Sachs 1966). Recently, the cytokinin profile of strain D188, which is correlated with the presence of pFiD188, has been identified and the modus operandi of the cytokinins uncovered (Pertry et al. 2009). Nevertheless, although the fas operon was the only candidate gene set to encode the cytokinin biosynthetic pathway, only circumstantial evidence was available to support this hypothesis (Crespi et al. 1992, 1994). By identifying the bioactive fractions in culture supernatants from different D188 derivatives, we demonstrated that the fas operon contributed to iP and $2 \mathrm{MeScZ}$ production. Subsequent determination of the cytokinin profiles of four fas mutants confirmed this result and identified the four Z-type cytokinins as the main fas cytokinins.

The biochemical analysis showed that the FasD enzyme produced cytokinins in vitro with a turnover rate $\left(\mathrm{k}_{\text {cat }}\right)$ that is comparable with that of plant Ipt (Abe et al. 2007). The relatively low $\mathrm{k}_{\mathrm{cat}}$ value points to a possible inhibition of the enzyme activity by the reaction product, which might indicate that in vivo FasD forms an enzyme complex with a protein that further converts the cytokinin produced by FasD. Similarly to the Ipt proteins from Agrobacterium tumefaciens (Krall et al. 2002), FasD can produce both iP and $\mathrm{tZ}$ in vitro. The comparable levels of $\mathrm{tZ}, \mathrm{cZ}$, and $2 \mathrm{MeScZ}$ in D188-fasA and D188-fasD supernatants, on the other hand, suggest that, in vivo, under the conditions tested, FasD might not produce hydroxylated cytokinins. However, it cannot be ruled out that, in planta, the conditions or precursor availability are such that FasD would contribute to Z-type cytokinin production during the interaction with the plant.

Extensive biochemical analysis of plant CKX enzymes has identified specific residues in the cytokinin-binding domain that are hypothesized to determine substrate specificity by interacting with the cytokinin molecules (Werner et al. 2006). The presence of an Asp-Glu pair that binds in the vicinity of the cytokinin N6 atom has been shown to be essential for effective degradation (Malito et al. 2004). The carboxylate-carboxylate couple can share a proton that stabilizes the substrate amino group in the binding site. However, FasE of $R$. fascians has an Asp-Gln pair instead, which is incapable of proton sharing and could, theoretically, reduce the catalytic efficiency. CKX enzymes with a preference for cytokinin bases usually have a Glu residue at the position that interacts with the N9 atom from the purine ring, whereas a preference for N9 glucosides or cytokinin nucleotides is characterized by an Ala or Ser residue (Galuszka et al. 2007). FasE has a Gln at this position, 
which is similar in size to Glu but bears an opposite charge that would repulse the N9 atom. Moreover, the conserved Asn/Tyr-Leu (Phe) motif in plant CKX, which is part of the substrate-binding cavity accommodating the C4-C5 carbons of the side chain, is replaced by Ser/Val-Asn in FasE, which could result in a different substrate specificity. Despite these atypical residues in the cytokinin-binding domain, FasE proved to be a functional CKX enzyme with a strong affinity for iP-type cytokinins, except for iP9G, and to degrade the fasproduced iP. Whereas the very efficient breakdown of $2 \mathrm{MeSiP}$ is also observed for the vacuolar CKX of Arabidopsis, the intermediate or low affinity for the Z-type cytokinins is comparable with the apoplastic Arabidopsis CKX, and the preference for iP and iPR is shared with all the Arabidopsis CKX enzymes (Pertry et al. 2009). FasE seems to be a CKX enzyme with a particular substrate specificity and, therefore, it is very unlikely that this protein has a biosynthetic function as previously postulated (Goethals et al. 2001). The rationale behind the presence of a CKX enzyme in a cytokinin biosynthetic cluster is puzzling. Possibly, FasE fine tunes the composition of the cytokinin spectrum produced by $R$. fascians during infection, which might be important for symptom development. Indeed, in vitro, when the six $R$. fascians cytokinins were supplied to the FasE protein, iP-type cytokinins were immediately depleted, whereas the Z-type cytokinins and their $2 \mathrm{MeS}$ derivatives were much more resistant to the oxidative cleavage. Alternatively, FasE might remove excess reaction product of FasD, preventing a feedback inhibition and, thus, ensuring a continuous cytokinin production. Finally, FasE might function as a detoxification enzyme to degrade nonsecreted cytokinins in the bacterial cytoplasm to prevent their accumulation to toxic levels. The comparable expression profiles of fas $\mathrm{E}$ and fas $\mathrm{A}$ during the interaction with the plant suggest that the CKX activity is required simultaneously with the main biosynthetic activity mediated by FasA-FasD. Although this observation does not allow the distinction between the two latter possible functions, the similar colonization capacity of D188-fasE and D188fasA (data not shown) are in support of an accessory function of FasD for FasE.

FasF, which is seemingly not involved in precursor delivery as previously hypothesized (Goethals et al. 2001), is a phosphoribohydrolase with a slight preference for iPR-5'-MP over tZR-5'-MP and cZR-5'-MP under the in vitro conditions tested. Nevertheless, the cytokinin profiles of the D188-fasF mutant indicate that the in vivo phosphoribohydrolase activity of the protein might be responsible for the release of $t Z$, $2 \mathrm{MeStZ}, \mathrm{cZ}$, and, to a lesser extent, $2 \mathrm{MeScZ}$ from their nucleotide precursors. Consequently, the level of the Z-type cytokinins seems to be determined both by FasD-FasA and FasF activity.

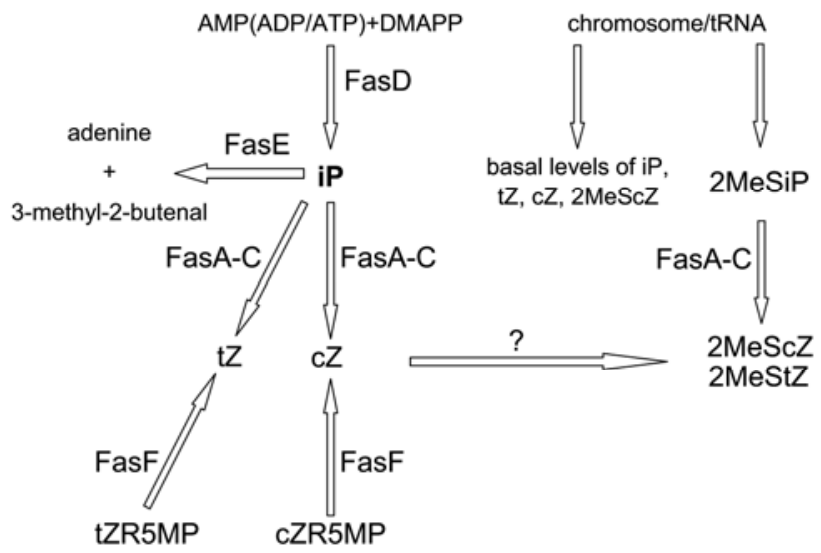

Fig. 4. Model of the Fas-mediated production of the cytokinin mixture.
Indeed, the comparable steady-state expression levels of fas $\mathrm{A}$ and fas $\mathrm{F}$ during the interaction with the plant suggest that both pathways contribute equally to the zeatin delivery required for symptom maintenance.

Based on the biochemical data and the cytokinin profiles, we assume that tRNA is the source of the basal but not the increased pathogenicity-related levels of the six cytokinin bases. The absolute dependence of $\mathrm{cZ}, \mathrm{tZ}$, and $2 \mathrm{MeStZ}$ levels on the entire fas operon and of $2 \mathrm{MeScZ}$ levels on FasA and FasD are important indications that these cytokinins are synthesized de novo. In our model, FasD is the key enzyme that synthesizes iP (and possibly $\mathrm{tZ}$ ) that serves as a precursor for other Fas enzymes (Fig. 4). FasA, as a putative P450 monooxygenase, hydroxylates iP to form $\mathrm{tZ}$ and $\mathrm{cZ}$. Fas A also hydroxylates chromosomally produced $2 \mathrm{MeSiP}$, yielding $2 \mathrm{MeScZ}$ and, probably, $2 \mathrm{MeStZ}$. The enzymes involved in the methylthiolation of iP, $\mathrm{tZ}$, and $\mathrm{cZ}$ to yield the $2 \mathrm{MeS}$ derivatives remain to be identified. FasF, as a phosphoribohydrolase, represents a complementary route for the production of the Z-type cytokinins. The FasE CKX activity is probably required for the optimal functioning of the FasD enzyme. A similar reaction mechanism may exist for the Fas proteins of Streptomyces turgidiscabies, a scab-causing phytopathogen, to date, the only other organism known to carry a fas operon (Joshi and Loria 2007).

The virulence phenotypes of the fas mutants revealed that each functional module and, consequently, each cytokinin mixture has a dedicated role in symptom development. FasD is the key to virulence-associated cytokinin production and, therefore, to symptom initiation. The absolute requirement of FasA for virulence and its very early and strong expression during the interaction substantiate the central position of the Z-type cytokinins in the modulation of plant development (Pertry et al. 2009). The transient virulence of D188-fasF indicates that FasF-mediated production of the zeatins is not essential for symptom induction but is a prerequisite for symptom maintenance. The activity of FasE seems important for efficient initiation of the hyperplasia. Together, these findings strengthen our previous statement that virulence is not a matter of specialized molecules but, rather, of concentrations and ratios (Pertry et al. 2009).

The transduction of the bacterial signals upon perception by the individual cytokinin receptors proved to be different: enhanced ARR5 expression mediated by CRE1/AHK4 was transient whereas that mediated by AHK3 was constitutive; hardly any differential ARR5 expression via AHK2 was observed. These results indicate that CRE1/AHK4-mediated signal perception and transduction is largely restricted to the initiation phase of symptom development when a high cytokinin sensitivity is desirable. Consequently, CRE1/AHK4 would be less important for the recognition of the FasF-mediated flow of zeatins that is co-responsible for symptom maintenance. Thus, the transient ARR5 expression in the CRE1/AHK4 background could reflect a shift in the cytokinins produced by the bacteria at the later time points of the infection, which is supported by the strongly reduced virulence of $\mathrm{D} 188-$ fas $\mathrm{F}$ and the different kinetics of fas gene expression during the interaction.

In conclusion, with detailed cytokinin profiling and enzyme analyses, we have shown that the fas-encoded machinery is responsible for the production of the virulence-associated level of cytokinin bases. The diversity of the virulence phenotypes of the different fas mutants together with fas gene expression profiles indicate that the production of a cytokinin mix is only part of the pathogenicity mechanism. Indeed, the relative concentrations of the different cytokinins in the mix and the secretion of a primary initiation wave and a secondary maintenance flow of cytokinins into the plant tissues seem equally important for symptom initiation and maintenance. Thus, rather than being 
brute-force hormone producers, $R$. fascians and, possibly, other hyperplasia-inducing phytopathogens are seemingly stealth masters in modulating plant physiology and development.

\section{MATERIALS AND METHODS}

Bacterial growth and induction conditions.

E. coli strains were grown at $37^{\circ} \mathrm{C}$ in Luria broth medium and $R$. fascians strains at $28^{\circ} \mathrm{C}$ in yeast extract broth (YEB) medium (Sambrook et al. 1989). When appropriate, media were supplemented with chloramphenicol $(\mathrm{Cm})$ at $25 \mu \mathrm{g} / \mathrm{ml}$, phleomycin at $1 \mu \mathrm{g} / \mathrm{ml}$, carbenicillin $(\mathrm{Cb})$ at $100 \mu \mathrm{g} / \mathrm{ml}$, or kanamycin $(\mathrm{Km})$ at $50 \mu \mathrm{g} / \mathrm{ml}$. To induce fas gene expression, $R$. fascians cultures were grown as described (Temmerman et al. 2000). In short, a 2-day-old $R$. fascians preculture was diluted 10 times in YEB medium. After overnight growth, the cells were washed and resuspended to an optical density at $600 \mathrm{~nm}$ $\left(\mathrm{OD}_{600}\right)=2.0$ in MinA medium $\left(0.1 \%\right.$ [wt/vol] $\mathrm{NH}_{4} \mathrm{SO}_{4}$, $0.025 \%$ [wt/vol] $\mathrm{MgSO}_{4}$, and $0.001 \%$ [wt/vol] thiamine, adjusted to $\mathrm{pH} 5.0$ using citric acid/sodium citrate as a buffer system). Finally, $20 \mathrm{mM}$ succinate and $5 \mathrm{mM}$ histidine were supplemented to generate the inducing conditions and the cultures were grown for $17 \mathrm{~h}$.

\section{Construction of overexpression plasmids and generation of fas-overexpressing strains.}

For the overexpression of the fas genes, the plasmids pRF37fasOE-A/F and pRF37fasOE-A/D were constructed. The fas $\mathrm{A}-\mathrm{F}$ and the fas A-D regions were amplified via PCR from genomic DNA of strain D188 with the primer pairs fasAstart-fasFend and fasAstart-fasDend (Supplementary Table 1), respectively, and cloned as XbaI/HindIII fragments into pRF37 (a bifunctional cloning vector for R. fascians) (Desomer et al. 1990), yielding the cloning intermediates pRF37fasA/F and pRF37fasA/D. The promoter of the att operon of $R$. fascians (Maes et al. 2001) was amplified via PCR from genomic DNA of strain D188 with the primers attpromstart and attpromend and cloned as an $\mathrm{XbaI}$ fragment into pRF37fas $\mathrm{A} / \mathrm{F}$ and pRF37fasA/D, yielding the final constructs pRF37fasOE-A/F and pRF37fasOE-A/D. These plasmids were introduced into D188-fas5 and D188-fasD (Crespi et al. 1992) via electroporation and selection on phleomycin (Desomer et al. 1990). Plasmid isolation and DNA cloning were done according to standard procedures (Sambrook et al. 1989).

\section{HPLC fractionation and immunopurification of bacterial supernatants and bioactive fractions.}

For the HPLC fractionation, 500-ml cell-free cultures of D188, D188-fasD, and D188-fas5OE-A/F were acidified with trifluoroacetic acid (TFA) to a final concentration of $0.1 \%$ (vol/vol), extracted over C18 cartridges (Sep-Pak; Waters, Milford, MA, U.S.A.), washed with $0.01 \% \mathrm{vol} / \mathrm{vol}$ TFA, and eluted with $80 \%$ methanol. The eluates were vacuum dried and resuspended in $500 \mu \mathrm{l}$ of $0.1 \%$ ( vol/vol) TFA in $2 \%$ (vol/vol) acetonitrile and filtered through $0.45-\mu \mathrm{m}$ Millex-HV units. Samples were analyzed by a Waters 625 LC System connected to a photodiode array detector (Waters) and fractionated over a reversephase column ( 4 by $250 \mathrm{~mm}$, Vydac, $218 \mathrm{TP}, \mathrm{C} 18,300 \AA$, with guard column; Alltech, Nicholasville, KY, U.S.A.) with water (A) and acetonitrile (B) as mobile phases. A linear gradient was set from 2 to $50 \%$ B for $30 \mathrm{~min}$ and from 50 to $100 \%$ B for 5 min, followed by a regeneration of $15 \mathrm{~min}$ in $2 \% \mathrm{~B}$. The flow rate was $1 \mathrm{ml} / \mathrm{min}$ and the eluates were collected every minute.

The collected fractions were vacuum dried and redissolved in $100 \mu \mathrm{l}$ of $80 \% \mathrm{MeOH}$, of which $10 \mu \mathrm{l}$ was used in the yeast bioassay to test for cytokinin activity (see below). With this approach, two fas-dependent fractions with significant cytokinin activity were identified that did not correlate with a distinct peak in the chromatogram. Subsequently, these fractions were pooled and subjected to a second separation with the same HPLC system and reverse-phase column with $10 \mathrm{mM}$ ammonium acetate (A) and 50/50 (vol/vol) $10 \mathrm{mM}$ ammonium acetate/acetonitrile (B). The gradient was set from 10 to $90 \% \mathrm{~B}$ for $20 \mathrm{~min}$, followed by a regeneration of $10 \mathrm{~min}$ in $10 \% \mathrm{~B}$. The flow rate, fraction collection, and testing of the bioactivity were the same as in the first HPLC. The bioactive fractions were finally further purified via immunopurification, as described (Novák et al. 2003).

\section{Identification of the cytokinins in the bioactive fractions.}

For the high-resolution identification of the cytokinins in the bioactive fractions, a hybrid quadrupole time-of-flight (QTOF) micromass-spectrometer (Waters) was used (von Schwartzenberg et al. 2007). Aliquots of $5 \mu \mathrm{l}$ from the $100-\mu \mathrm{l}$ resuspension were fractionated on a reversed-phase column Symmetry C18 (300 $\mu \mathrm{m}$ by $150 \mathrm{~mm}, 5 \mu \mathrm{m}$; Waters) on a CapLC separation module (Waters). Following the injection, analytes were eluted with a 60-min binary linear gradient of 15 $\mathrm{mM} \mathrm{HCOONH} 4(\mathrm{pH} \mathrm{4})(\mathrm{A})$ and methanol (B) (0 to $1 \mathrm{~min}$, $30 \% \mathrm{~B} ; 1$ to $20 \mathrm{~min}, 50 \% \mathrm{~B} ; 20$ to $36 \mathrm{~min}, 100 \% \mathrm{~B} ; 36$ to 45 min, $100 \% \mathrm{~B}$; 45 to $60 \mathrm{~min}, 30 \% \mathrm{~B}$; flow rate, $7 \mu \mathrm{l} / \mathrm{min}$; column temperature, $30^{\circ} \mathrm{C}$ ). Electrospray ionization in the positive ion mode was carried out with the following parameters: source block and desolvation temperature, 90 and $200^{\circ} \mathrm{C}$; capillary and cone voltage, 2,500 and $28 \mathrm{~V}$; and spray and cone gas flow $\left(\mathrm{N}_{2}\right), 50$ and 200 liters/h. In the full-scan mode, data were acquired in the mass range $\mathrm{m} / \mathrm{z}, 50$ to 1,000 , with a $33-\mathrm{ms}$ pusher cycle time, a 2.0-s scan time, and a $4-\mathrm{eV}$ collision energy. For the exact mass determination experiments, a lock spray was used for external calibration with a mixture of $0.1 \mathrm{M}$ $\mathrm{NaOH}$ and $10 \%$ (vol/vol) formic acid and acetonitrile (1:1:8 by volume) as a reference. Accurate masses were calculated and used for the determination of the elementary composition of the analytes with a 5-ppm fidelity.

\section{Yeast bioassay.}

Saccharomyces cerevisiae $\sin 1 \Delta$ carrying the plasmid p415CYC-CRE1 (Inoue et al. 2001) was maintained at $28^{\circ} \mathrm{C}$ on solid yeast nitrogen base (YNB) medium (YNB at 6.7 $\mathrm{g} /$ liter, DO supplement -Ura/-His/-Leu at $0.65 \mathrm{~g} / \mathrm{liter}$, and 0.8 $\mathrm{mM}$ His [final concentration]), supplemented with $2 \%$ (wt/vol) galactose. For the bioassay, $50 \mu \mathrm{l}$ of an aqueous yeast suspension was diluted in $20 \mathrm{ml}$ of YNB medium supplemented with $2 \%$ (wt/vol) glucose; aliquots of $190 \mu \mathrm{l}$ were added to a 48well plate. To test their cytokinin activity, the fractions were resuspended in $100 \mu \mathrm{l}$ of water and $10 \mu \mathrm{l}$ was added to each well. As a negative control, water was added and, as a positive control, $10 \mu \mathrm{M} \mathrm{tZ}$. The plates were incubated at $28^{\circ} \mathrm{C}$ and growth was scored after 2 days.

\section{Polyamine analysis.}

Supernatants of strain D188 and infected tobacco tissue were freeze dried, homogenized, derivatized with dansylchloride, and analyzed for their polyamine content as described (Scaramagli et al. 1999). Analyses (three replicates) were done on three biological repeats.

\section{Construction of fas $\mathrm{D}$, fas $\mathrm{E}$, and fas $\mathrm{F}$ expression vectors.}

A fas $\mathrm{D}$ expression vector was generated with the Gateway recombinant cloning technology (Invitrogen, Carlsbad, CA, U.S.A.). The coding region of fas $D$ was amplified via PCR with the FasDHisstart and FasDHisend primers flanked by the attB recombination sites and cloned into the entry vector pDONR221 (Invitrogen) via att site recombination, and the 
sequence was verified. Subsequently, the gene was cloned via att site recombination into the destination vector pDEST17 (Invitrogen), which generated an $\mathrm{N}$-terminal His-tagged recombinant protein. This construct pDEST17fasD was introduced into $E$. coli BL21 Star (DE3) via heat-shock transformation and selection on $\mathrm{Cb}$.

For the enzymatic analyses of the FasE and FasF proteins, two plasmids were generated producing a FasE-MBP or a FasF-MBP fusion protein. The fasE gene was amplified via PCR with the primers fasEMBPstart and fasEMBPend, and the fas $\mathrm{F}$ gene with the primers fasFMBPstart and fasFMBPend. The PCR fragments were cloned as XbaI/HindIII fragments in the pMALc2 vector system (Kellerman and Ferenci 1982), resulting in the plasmids pMALfasE and pMALfasF that were introduced into $E$. coli BL21 Star (DE3) via heat-shock transformation and selection on $\mathrm{Cb}$.

\section{Purification of the recombinant proteins.}

Transformants carrying the plasmid pDEST17fasD were grown in Luria broth medium, supplemented with $\mathrm{Cb}$ and $1 \%$ (wt/vol) glucose at $37^{\circ} \mathrm{C}$ with shaking until $\mathrm{OD}_{600}=0.6$, after which fas D expression was induced by incubation with $0.4 \mathrm{mM}$ isopropyl $\beta$-D-1-thiogalactopyranoside at $20^{\circ} \mathrm{C}$ for $17 \mathrm{~h}$. Cells were harvested by centrifugation $\left(2,000 \times g, 30 \mathrm{~min}, 4^{\circ} \mathrm{C}\right)$ and pellets were resuspended in lysis/equilibration buffer $(50 \mathrm{mM}$ Tris/ $\mathrm{HCl}$ [pH 7.0], $300 \mathrm{mM} \mathrm{NaCl}, 10 \mathrm{mM}$ imidazole, $10 \mathrm{mM} \beta$ mercapto ethanol, $10 \mathrm{mM} \mathrm{NaCl}$, and $9 \%$ [wt/vol] glycerol). Lysozyme $(0.75 \mathrm{mg} / \mathrm{ml})$ and a protease inhibitor cocktail (Sigma-Aldrich, St. Louis) were added and the sample was incubated at $37^{\circ} \mathrm{C}$ for $15 \mathrm{~min}$. All lysis and purification steps were done at $4^{\circ} \mathrm{C}$. The cell suspension was disrupted by a freeze-thaw procedure, after which the lysate was centrifuged for $20 \mathrm{~min}$ at $16,100 \times g$ and $4^{\circ} \mathrm{C}$. The supernatant was applied on a Talon resin affinity column (Clontech Laboratories, Palo Alto, CA, U.S.A.), previously equilibrated by lysis/equilibration buffer according to the manufacturer's instructions. The loaded column was rotated at $4^{\circ} \mathrm{C}$ for $30 \mathrm{~min}$ and, subsequently, washed twice with washing buffer $(50 \mathrm{mM}$ Tris, $300 \mathrm{mM} \mathrm{NaCl}$, and $10 \mathrm{mM}$ imidazole, $\mathrm{pH}$ 7.0). The sample was eluted with $3 \mathrm{ml}$ of elution buffer (150 mM imidazole, $300 \mathrm{mM} \mathrm{NaCl}, 50 \mathrm{mM}$ Tris, and $9 \%$ [vol/vol] glycerol). The average amount of eluted His-FasD protein was $0.2 \mathrm{mg} / \mathrm{ml}$ with a 80 to $90 \%$ homogeneity as determined by sodium dodecyl sulfate polyacrylamide gel electrophoresis (SDS-PAGE). followed by protein gel blotting with anti-His-tag antibodies (Sigma-Aldrich).

FasF-MBP and FasE-MBP were purified from transformants carrying the plasmid pMALfasE or pMALfasF, respectively, according to Riggs (2000). Free FasE and FasF was obtained by overnight factor Xa protease treatment $(1 \mu \mathrm{g}$ of protease per 100 $\mu \mathrm{g}$ of protein) (Sigma-Aldrich) of concentrated protein samples ( 25 to $30 \mathrm{mg} / \mathrm{ml}$ ) supplemented with $10 \mathrm{mM} \mathrm{CaCl}_{2}$ at $22^{\circ} \mathrm{C}$. The quality of the samples $(+\mathrm{Xa} /-\mathrm{Xa})$ was verified by SDS-PAGE prior to testing their enzymatic activity. The protein concentrations were measured with the BCA Protein Assay (Bio-Rad, Hercules, CA, U.S.A.) with bovine serum albumin as a standard.

\section{Ipt activity assay.}

Purified His-FasD protein $(4 \mu \mathrm{g})$ was added to the reaction mixture $(\mathrm{pH} 8.0 ; 1 \mathrm{M}$ betaine, $30 \mathrm{mM}$ Tris, $50 \mathrm{mM} \mathrm{KCl}, 10$ $\mathrm{mM} \mathrm{MgCl}_{2}$, and $5 \mathrm{mM} \beta$-mercaptoethanol). To determine the preferred side-chain acceptor and donor, the reaction mixture contained $25 \mu \mathrm{M}$ DMAPP as donor and 0.001 to $3.2 \mu \mathrm{M}$ AMP, ADP, or ATP as substrate, or $2 \mu \mathrm{M}$ AMP as acceptor and 0.001 to $1 \mu \mathrm{M}$ DMAPP or HMBPP as donor, respectively. After incubation for $1,2,4,30$, and $60 \mathrm{~min}$ at $25^{\circ} \mathrm{C}$, the reactions were stopped by freezing in liquid nitrogen and subsequent heating for $10 \mathrm{~min}$ at $96^{\circ} \mathrm{C}$. Finally, samples were treated with calf intestine alkaline phosphatase (Fermentas International, Burlington, Ontario, Canada) for $30 \mathrm{~min}$.

To estimate the FasD Ipt activity, the iPR and ZR reaction products were quantified in all samples in flat-bottom plates (MaxiSorp; Thermo Fisher Scientific, NUNC, Roskilde, Denmark) by enzyme-linked immunosorbent assay with a specific anti-iPR and anti-ZR rabbit polyclonal antibody (Laboratory of Plant Growth Regulators, Olomouc, Czech Republic) as described, but with slight modifications (Strnad et al. 1990). iPR and TZR concentrations were calculated based on a sigmoidal plot of their standard curves. All the measurements were done in triplicate. The kinetic parameters were derived from data obtained from Michaelis-Menten plottings with the Hyper32 software.

\section{TLC of supernatant extracts.}

Cultures (1 ml each) of strains D188, D188-fasD, D188fas DOE-A/F, and D188-fasDOE-A/D were grown under fasinducing conditions (Temmerman et al. 2000). After $7 \mathrm{~h}, \mathrm{U}-{ }^{14} \mathrm{C}$ adenine (GE Healthcare, Little Chalfont, U.K.) at $2.5 \mu \mathrm{Ci} / \mathrm{ml}$ was added. Ten hours later, the labeled cultures were centrifuged at $10,500 \times g$ for $10 \mathrm{~min}$ and the obtained supernatants were acidified with TFA to a final concentration of $0.1 \%$ (vol/vol) and passed over C18 cartridges (Sep-Pak; Waters) according to the manufacturer's instructions. The cartridges were washed with $0.01 \%$ (vol/vol) TFA and eluted with $80 \%$ methanol. The eluates were vacuum dried and resuspended in $10 \mu \mathrm{l}$ of water, analyzed on silica plates (Polygram Sil G/UV $\mathrm{UV}_{254}$; Macherey-Nagel, Düren, Germany) that were first washed with $100 \%$ methanol for $30 \mathrm{~min}$, subsequently dried in the air, and resolved for $1 \mathrm{~h}$ with equilibrated butanol as mobile phase (obtained from $25 \%$ butanol/water/ammonia [4:2:1, $\mathrm{vol} / \mathrm{vol} / \mathrm{vol}]$ ). After drying in the air, plates were placed for 12 $\mathrm{h}$ in a phospho-imager cassette for visualization.

\section{CKX enzyme assay.}

For the cytokinin dehydrogenase enzyme assay (Pertry et al. 2009), the reaction mixture contained $100 \mathrm{mM}$ McIlvaine buffer ( $\mathrm{pH}$ 6.0), 2 to $20 \mu \mathrm{g}$ of FasE protein, $50 \mu \mathrm{M}$ cytokinin substrate, and 50 to $500 \mu \mathrm{M}$ electron acceptor. The oxidase assay was done as described (Frébort et al. 2002). For the experiments with multiple cytokinins, similar reaction mixtures were set up but the cytokinin concentrations were reduced to 1 $\mu \mathrm{M}$. At defined time points, 50- $\mu \mathrm{l}$ aliquots were removed from the reaction mixture and supplemented with 1\% TFA to stop the reaction. After a 5-min centrifugation at $14,000 \times g$, the samples were diluted 10 times with the mobile phase and the remaining cytokinins analyzed as described above.

\section{Phosphoribohydrolase activity assay.}

For the cytokinin nucleoside phosphoribohydrolase enzyme assay, the reaction mixture, containing $100 \mathrm{mM}$ Mcllvaine buffer ( $\mathrm{pH} 7.0$ ), $160 \mu \mathrm{g}$ of FasF-MBP protein, $1 \mu \mathrm{M}$ each $\mathrm{tZ}$, $\mathrm{cZ}$, and iP nucleoside $5^{\prime}-\mathrm{MP}$, was incubated at $30^{\circ} \mathrm{C}$. At defined time points, $100-\mu \mathrm{l}$ aliquots were removed from the reaction mixture and supplemented with $1 \%$ (vol/vol) TFA to stop the reaction. After a 5-min centrifugation at $14,000 \times g$, the samples were diluted 10 times with the mobile phase and the remaining cytokinins analyzed as described above.

\section{Insertion mutagenesis of $\boldsymbol{R}$. fascians and generation of fas gene reporter strains.}

Two new fas insertion mutants were isolated via disruptive single homologous recombination (Crespi et al. 1994). Therefore, the nonreplicating plasmids pSPIPfasEgus and $\mathrm{pCR} \Delta$ fas $\mathrm{F}$ were constructed. For the mutation of fas $\mathrm{E}$, an internal fas $\mathrm{E}$ fragment was amplified via PCR with the primers fasEGUSstart 
and fasEGUSend, first cloned into pGUS1 (Desomer et al. 1992; Van den Eede et al. 1992) as a PstI-NcoI fragment generating a translational fasE-uidA fusion, then into pSP72 (Promega, Madison, WI, U.S.A.) as a HindIII-XbaI fragment, and, finally, the $\mathrm{Cm}$ resistance gene was introduced as an $\mathrm{XbaI}$ fragment (Desomer et al. 1990), generating the final construct pSPIPfasEgus that can be used simultaneously for mutagenesis and expression analysis. For the mutation of fas $\mathrm{F}$, an internal fas $\mathrm{F}$ fragment was amplified via $\mathrm{PCR}$ with the primers $\Delta$ fasFstart and $\Delta$ fasFend and cloned into pCRBlunt (Invitrogen), generating the final construct, $\mathrm{pCR} \Delta$ fas $\mathrm{F}$.

For expression analysis, two additional nonreplicating plasmids, pSPIPfasAgus and pSPIPfasFgus, were constructed. The PCR-amplified internal fas A fragment (primers fasAGUSstart and fasAGUSend) was first cloned into pGUS1 (Desomer et al. 1992; Van den Eede et al. 1992) as a SphI-NcoI fragment and, subsequently, using the same cloning steps as for the generation of pSPIPfasEgus, the final construct pSPIPfasFgus was obtained. Similarly, after subcloning of the PCR-amplified internal fas $\mathrm{F}$ fragment (primers fasFGUSstart and fasFGUSend) into pGUS1 (Desomer et al. 1992; Van den Eede et al. 1992) as a $P s t \mathrm{I}-N c o$ I fragment and subsequent cloning steps, the final construct pSPIPfasEgus was obtained.

After introduction of these four plasmids into strain D188 via electrotransformation (Desomer et al. 1990) and selection on $\mathrm{Cm}$ (pSPIPfasAgus, pSPIPfasEgus, and pSPIPfasFgus) or $\mathrm{Km}$ (pCR $\Delta$ fas F), correct recombinations into the fas operon were verified by DNA gel-blot hybridization with gene-specific probes.

\section{Bacterial cytokinin measurements.}

The quantification of the cytokinins in the supernatant of the fas mutants was as described (Pertry et al. 2009). Three independent preparations were analyzed for each strain. The significance of the observed quantitative differences of the means for each cytokinin in each strain was assessed by pairwise comparisons using the Tukey range test in conjunction with an analysis of variance. Values were considered significantly different when $P<0.05$.

\section{Plant growth conditions, infection, and sampling.}

Arabidopsis thaliana (L.) Heynh. and N. tabacum (L.) W38 seeds were sterilized by rinsing for $2 \mathrm{~min}$ in $70 \%$ (vol/vol) $\mathrm{EtOH}$ and $12 \mathrm{~min}$ in a $5 \%$ (wt/vol) $\mathrm{NaOCl}$ solution supplemented with $0.1 \%$ ( vol $/ \mathrm{vol})$ Tween20, then washing with sterile water. Seeds were germinated and grown on half-strength (Arabidopsis) or full-strength (tobacco) Murashige and Skoog medium in a growth chamber with $16 \mathrm{~h}$ of light and $8 \mathrm{~h}$ of darkness.

Prior to infections, 2-day-old $R$. fascians cultures were washed and concentrated four times in sterile water. For tobacco seedling infection, seeds were germinated for 5 days, until the radicle emerged, after which $20 \mu \mathrm{l}$ of the proper bacterial culture or mix of cultures was applied. At 14, 28, and 45 dpi, phenotypes were scored and quantified for at least 50 plants per strain. For the quantification of fas gene expression during the interaction, four plants per time point and per bacterial strain were sampled at $0,1,2,4,7,14,28$, and 45 dpi and processed as described below.

The transgenic Arabidopsis lines were infected at developmental stage 1.05 (16 days old with five visible leaves) (Boyes et al. 2001) by applying $20 \mu \mathrm{l}$ of the bacterial culture to the shoot apex. Plants were sampled at 2, 4, 10, 17, and 31 dpi for histochemical and qRT-PCR analyses.

\section{Expression of the fas genes.}

For the expression analysis, tobacco seedlings were infected and sampled as described above. Extracts were prepared by crushing the plants in $500 \mu \mathrm{l}$ of water with a pestle in an Eppendorf tube, of which $50 \mu \mathrm{l}$ was used for serial dilutions to determine the number of CFU. Then, $500 \mu \mathrm{l}$ of twofold concentrated MUG buffer (100 mM NaPO 4 [pH 7.0], $20 \mathrm{mM} \beta$ mercapto ethanol, $20 \mathrm{mM}$ EDTA, $0.2 \%$ SDS, and $0.2 \%$ Triton $\mathrm{X}-100)$ and the substrate 4-methylumbelliferyl- $\beta$-D-glucuronide (final concentration $0.1 \mathrm{mM}$ ) were added to the plant material. The mixture was incubated at $37^{\circ} \mathrm{C}$ and, at 15,30 , and 60 $\mathrm{min}$, the reaction was stopped by adding 50- $\mu$ l aliquots to 200 $\mu \mathrm{l}$ of $200 \mathrm{mM} \mathrm{Na} \mathrm{CO}_{3}$ in black Polysorb 96-well plates (NUNC, Roskilde, Denmark). GUS activity was determined by excitation at $365 \mathrm{~nm}$ and measurement at $460 \mathrm{~nm}$ (Fluostar optima reader) and was calculated as the measured emission/ [time $(\mathrm{min}) \times \log (\mathrm{CFU})]$. Data are the average of three technical repeats.

\section{Histochemical staining and qRT-PCR analysis.}

For GUS staining, entire plants were sampled and analyzed as described (Depuydt et al. 2008a). The three biological repeats each consisted of at least five plants per treatment. For the qRT-PCR analysis, during sample collection, the tissue was snap frozen in liquid nitrogen and stored at $-80^{\circ} \mathrm{C}$ until further processing. RNA isolation, cDNA synthesis, and qRT-PCR were carried out as described (Depuydt et al. 2008a). The mean expression level of each gene was calculated from three independent biological repeats. The $\log _{2}$ transformation values of these data were used for the conversion to heat maps with the TMEV-3D software (Multiexperiment Viewer; The Institute for Genome Research, Rockville, MD, U.S.A.).

\section{ACKNOWLEDGMENTS}

This work was supported, in part, by the Ministry of Education, Youth and Sports of the Czech Republic (grant no MSM 6198959216 to L. Spíchal, P. Galuszka, M. Strnad, O. Novák, and P. Tarkowski; grant no LC06034 to L. Spíchal and M. Strnad); the Grant Agency of the Czech Republic (522/08/H003 to K. Václavíková and M. Gemrotová); the University of Bologna (RFO Grant to S. Biondi); the "Agenschap voor innovatie door Wetenschap en Technologie" (predoctoral fellowship to I. Pertry); the "Bijzondere Onderzoeksfonds" of Ghent University (predoctoral fellowship to S. Depuydt); and the Research Foundation-Flanders (predoctoral fellowship to E. Stes). I. Pertry was the recipient of a European Molecular Biology Organization short-term fellowship. We thank T. Kakimoto for providing the $S$. cerevisiae $\sin 1 \Delta$ [p415CYC1CRE1] strain, O. Blahoušek for initiating part of the identification work, P. Efler for preliminary experiments with CKX, J. Den Herder for technical assistance, P. De Backer for the phylogenetic analysis of FasE, I. Frébort and M. Jaziri for stimulating discussions, and R. De Schepper and M. De Cock for help in preparing the manuscript.

\section{LITERATURE CITED}

Abe, I., Tanaka, H., Abe, T., and Noguchi, H. 2007. Enzymatic formation of unnatural cytokinin analogs by adenylate isopentenyltransferase from mulberry. Biochem. Biophys. Res. Commun. 355:795-800.

Anton, B. P., Saleh, L., Benner, J. S., Raleigh, E. A., Kasif, S., and Roberts, R. J. 2008. RimO, a MiaB-like enzyme, methylthiolates the universally conserved Asp88 residue of ribosomal protein S12 in Escherichia coli. Proc. Natl. Acad. Sci. U.S.A. 105:1826-1831.

Baron, K., and Stasolla, C. 2008. The role of polyamines during in vivo and in vitro development. In Vitro Cell. Dev. Biol. Plant 44:384-395.

Boyes, D. C., Zayed, A. M., Ascenzi, R., McCaskill, A. J., Hoffman, N. E., Davis, K. R., and Görlach, J. 2001. Growth stage-based phenotypic analysis of Arabidopsis: A model for high throughput functional genomics in plants. Plant Cell 13:1499-1510.

Chatfield, J. M., and Armstrong, D. J. 1986. Regulation of cytokinin oxidase activity in callus tissues of Phaseolus vulgaris L. cv. Great Northern. Plant Physiol. 80:493-499.

Cornelis, K., Maes, T., Jaziri, M., Holsters, M., and Goethals, K. 2002. Virulence genes of the phytopathogen Rhodococcus fascians show specific spatial and temporal expression patterns during plant infection. Mol. Plant-Microbe Interact. 15:398-403.

Crespi, M., Messens, E., Caplan, A. B., Van Montagu, M., and Desomer, J. 
1992. Fasciation induction by the phytopathogen Rhodococcus fascians depends upon a linear plasmid encoding a cytokinin synthase gene. EMBO (Eur. Mol. Biol. Organ.) J. 11:795-804.

Crespi, M., Vereecke, D., Temmerman, W., Van Montagu, M., and Desomer, J. 1994. The fas operon of Rhodococcus fascians encodes new genes required for efficient fasciation of host plants. J. Bacteriol. 176:2492-2501.

Depuydt, S., Doležal, K., Van Lijsebettens, M., Moritz, T., Holsters, M., and Vereecke, D. 2008a. Modulation of the hormone setting by Rhodococcus fascians results in ectopic KNOX activation in Arabidopsis. Plant Physiol. 146:1267-1281.

Depuydt, S., Putnam, M., Holsters, M., and Vereecke, D. 2008b. Rhodococcus fascians, an emerging threat for ornamental crops. Pages 480489 in: Floriculture, Ornamental and Plant Biotechnology: Advances and Topical Issues, Vol. V, 1st. ed. J. A. Teixeira da Silva, ed. Global Science Books, London.

Depuydt, S., De Veylder, L., Holsters, M., and Vereecke, D. 2009. Eternal youth, the fate of developing Arabidopsis leaves upon Rhodococcus fascians infection. Plant Physiol. 149:1387-1398.

Desomer, J., Dhaese, P., and Van Montagu, M. 1990. Transformation of Rhodococcus fascians by high-voltage electroporation and development of $R$. fascians cloning vectors. Appl. Environ. Microbiol. 56:2818-2825.

Desomer, J., Vereecke, D., Crespi, M., and Van Montagu, M. 1992. The plasmid-encoded chloramphenicol resistance protein of Rhodococcus fascians is homologous to the transmembrane tetracycline efflux proteins. Mol. Microbiol. 6:2377-2385.

Einset, J. W., and Skoog, F. K. 1977. Isolation and identification of ribosyl-cis-zeatin from transfer RNA of Corynebacterium fascians. Biochem. Biophys. Res. Commun. 79:1117-1121.

Frébort, I., Sebeka, M., Galuszka, P., Werner, T., Schmülling, T., and Peč, P. 2002. Cytokinin oxidase/cytokinin dehydrogenase assay: Optimized procedures and applications. Anal. Biochem. 306:1-7.

Galuszka, P., Popelková, H., Werner, T., Frébortová, J., Pospíšilová, H. Mik, V., Köllmer, I., Schmülling, T., and Frébort, I. 2007. Biochemical characterization of cytokinin oxidases/dehydrogenases from Arabidopsis thaliana expressed in Nicotiana tabacum L. J. Plant Growth Regul. 26:255-267.

Goethals, K., Vereecke, D., Jaziri, M., Van Montagu, M., and Holsters, M. 2001. Leafy gall formation by Rhodococcus fascians. Annu. Rev. Phytopathol. 39:27-52.

Heyl, A., Werner, T., and Schmülling, T. 2006. Cytokinin metabolism and signal transduction. Page 93-123 in: Plant Hormone Signaling, Annual Plant Reviews. P. Hedden and S. Thomas, eds. Blackwell Publishing Ltd., Oxford

Inoue, T., Higuchi, M., Hashimoto, Y., Seki, M., Kobayashi, M., Kato, T., Tabata, S., Shinozaki, K., and Kakimoto, T. 2001. Identification of CRE1 as a cytokinin receptor from Arabidopsis. Nature 409:1060-1063.

Joshi, M., and Loria, R. 2007. Streptomyces turgidiscabies possesses a functional cytokinin biosynthetic pathway and produces leafy galls. Mol. Plant-Microbe Interact. 20:751-758.

Kakimoto, T. 2003. Biosynthesis of cytokinins. J. Plant Res. 116:233-239.

Kellerman, O. K., and Ferenci, T. 1982. Maltose-binding protein from Escherichia coli. Methods Enzymol. 90:459-463.

Krall, L., Raschke, M., Zenk, M. H., and Baron, C. 2002. The Tzs protein from Agrobacterium tumefaciens $\mathrm{C} 58$ produces zeatin riboside 5'-phosphate from 4-hydroxy-3-methyl-2-(E)-butenyl diphosphate and AMP. FEBS (Fed. Eur. Biochem. Soc.) Lett. 527:315-318.

Kurakawa, T., Ueda, N., Maekawa, M., Kobayashi, K., Kojima, M., Nagato, Y., Sakakibara, H., and Kyozuka, J. 2007. Direct control of shoot meristem activity by a cytokinin-activating enzyme. Nature 445:652-655.

Kuroha, T., Tokunaga, H., Kojima, M., Ueda, N., Ishida, T., Nagawa, S., Fukuda, H., Sugimoto, K., and Sakakibara, H. 2009. Functional analyses of LONELY GUY cytokinin-activating enzymes reveal the importance of the direct activation pathway in Arabidopsis. Plant Cell 21:3152-3169.

Maes, T., Vereecke, D., Ritsema, T., Cornelis, K., Ngo Thi Thu, H., Van Montagu, M., Holsters, M., and Goethals, K. 2001. The att locus of Rhodococcus fascians strain D188 is essential for full virulence on tobacco through the production of an autoregulatory compound. Mol. Microbiol. 42:13-28.

Malito, E., Coda, A., Bilyeu, K. D., Fraaije, M. W., and Mattevi, A. 2004. Structures of Michaelis and product complexes of plant cytokinin dehydrogenase: Implications for flavoenzyme catalysis. J. Mol. Biol. 341:1237-1249.

Matsubara, S., Armstrong, D. J., and Skoog, F. 1968. Cytokinins in tRNA of Corynebacterium fascians. Plant Physiol. 43:451-453.
Miyawaki, K., Tarkowski, P., Matsumoto-Kitano, M., Kato, T., Sato, S Tarkowska, D., Tabata, S., Sandberg, G., and Kakimoto, T. 2006. Roles of Arabidopsis ATP/ADP isopentenyltransferases and tRNA isopentenyltransferases in cytokinin biosynthesis. Proc. Natl. Acad. Sci. U.S.A. 103:16598-16603.

Novák, O., Tarkowski, P., Tarkowska, D., Doležal, K., Lenobel, R., and Strnad, M. 2003. Quantitative analysis of cytokinins in plants by liquid chromatography_-single-quadrupole mass spectrometry. Anal. Chim. Acta 480:207-218.

Pertry, I., Václavíková, K., Depuydt, S., Galuszka, P., Spíchal, L., Temmerman, W., Stes, E., Schmülling, T., Kakimoto, T., Van Montagu, M., Strnad, M., Holsters, M., Tarkowski, P., and Vereecke, D. 2009. Identification of Rhodococcus fascians cytokinins and their modus operandi to reshape the plant. Proc. Natl. Acad. Sci. U.S.A. 106:929-934.

Riefler, M., Novak, O., Strnad, M., and Schmülling, T. 2006. Arabidopsis cytokinin receptor mutants reveal functions in shoot growth, leaf senescence, seed size, germination, root development, and cytokinin metabolism. Plant Cell 18:40-54.

Riggs, P. 2000. Expression and purification of recombinant proteins by fusion to maltose-binding protein. Mol. Biotechnol. 15:51-62.

Romanov, G. A., Kieber, J., and Schmülling, T. 2002. A rapid cytokininresponse assay in Arabidopsis indicates a role for phospholipase D in cytokinin signaling. FEBS (Fed. Eur. Biochem. Soc.) Lett. 515:39-43.

Sakakibara, H. 2006. Cytokinins: Activity, biosynthesis, and translocation. Annu. Rev. Plant Biol. 57:431-449.

Sambrook, J., Fritsch, E. F., and Maniatis, T. 1989. Molecular Cloning: A Laboratory Manual, 2nd ed. Cold Spring Harbor Laboratory Press, Cold Spring Harbor, NY, U.S.A.

Scaramagli, S., Franceschetti, M., Michael, A. J., Torrigiani, P., and Bagni, N. 1999. Polyamines and flowering: Spermidine biosynthesis in the different whorls of developing flowers of Nicotiana tabacum L. Plant Biosyst. 133:229-237.

Schmülling, T., Werner, T., Riefler, M., Krupková, E., and Bartrina y Manns, I. 2003. Structure and function of cytokinin oxidase/dehydrogenase genes of maize, rice, Arabidopsis and other species. J. Plant Res. 116:241-252.

Spíchal, L., Werner, T., Popa, I., Riefler, M., Schmülling, T., and Strnad, M. 2009. The purine derivative PI-55 blocks cytokinin action via receptor inhibition. FEBS (Fed. Eur. Biochem. Soc.) J. 276:244-253.

Stirk, W. A., Novák, O., Václavíková, K., Tarkowski, P., Strnad, M., and van Staden, J. 2008. Spatial and temporal changes in endogenous cytokinins in developing pea roots. Planta 227:1279-1289.

Strnad, M., Vaněk, T., Binarová, P., Kamínek, M., and Hanuš, J. 1990. Enzyme immunoassays for cytokinins and their use for immunodetection of cytokinins in alfalfa cell culture. Pages 41-54 in: Molecular Aspects of Hormonal Regulation of Plant Development (Proc. Symp. 39 Colloquia 30 and 31 14th Biochem. Congr. Prague, Czechoslovakia). M. Kutáček, M. C. Elliott, and I. Macháčková, eds. SPB Academic Publishing, The Hague.

Temmerman, W., Vereecke, D., Dreesen, R., Van Montagu, M., Holsters, M., and Goethals, K. 2000. Leafy gall formation is controlled by fasR, an AraC-type regulatory gene in Rhodococcus fascians. J. Bacteriol. 182:5832-5840.

Thimann, K. V., and Sachs, T. 1966. The role of cytokinins in the "fasciation" disease caused by Corynebacterium fascians. Am. J. Bot. 53:731739.

Van den Eede, G., Deblaere, R., Goethals, K., Van Montagu, M., and Holsters, M. 1992. Broad host range and promoter selection vectors for bacteria that interact with plants. Mol. Plant-Microbe Interact. 5:228 234.

Veach, Y. K., Martin, R. C., Mok, D. W. S., Malbeck, J., Vankova, R., and Mok, M. C. 2003. $O$-glucosylation of cis-zeatin in maize. Characterization of genes, enzymes, and endogenous cytokinins. Plant Physiol. 131:1374-1380.

von Schwartzenberg, K., Fernández Núñez, M., Blaschke, H., Dobrev, P. I., Novák, O., Motyka, V., and Strnad, M. 2007. Cytokinins in the bryophyte Physcomitrella patens: Analyses of activity, distribution, and cytokinin oxidase/dehydrogenase overexpression reveal the role of extracellular cytokinins. Plant Physiol. 145:786-800.

Werner, T., Köllmer, I., Bartrina, I., Holst, K., and Schmülling, T. 2006. New insights into the biology of cytokinin degradation. Plant Biol 8:371-381.

\section{AUTHOR-RECOMMENDED INTERNET RESOURCE}

Hyper32 software: www.liv.ac.uk/ jse/software.html 